\title{
FAKTOR RISIKO KEPADATAN LALAT DAN SANITASI RUMAH DENGAN KEJADIAN DIARE DI KELURAHAN TANJUNG PINANG KOTA JAMBI TAHUN 2017
}

\author{
Listautin $^{1}$
}

\begin{abstract}
Diarrhea is one of health problem in the world including Indonesia. The Morbidity survey undertaken by Sub-Directorate of diarrhea, Health Department from 2007 to 2010is improved. According to the data gained from Puskesmas in Tanjung Pinang Jambi in 2017, it is found out that 5 different districs in Tanjung Pinang are the district which has the highest rate of diarrhea sufferers. The aim of this study is to find out the risk factors of the flies density and the dwelling sanitation to the occurance of diarrhea in Tanjung Pinang Jambi in 2017. This study is quantitative study by using case control design. The sample of this study is 68 people who consists of 34 samples of case group and 34 samples of control group. This study is analyzed through univariate and bivariate analysis by using chi-square test. The instruments of this study are the reviewed document, ceklist, and the measurement through fly grill. The result of analysis are found out that toilet is the main risk factor for the occurance of diarrhea with odds ratio (OR) value is 3,519. Sewerage (SPAL) is one the risk factor of the diarrhea occurance with odds ratio $(O R)$ value is 3,361. The waste is the other risk factors for the occurance of diarrhea with odds ratio $(O R)$ value is 4,418. The flies density is the protective factor for the diarrhea occurance with odds ratio $(O R)$ value is 0,773 .

Based on the result of this study, it can be concluded that it is necesarry to do the coorporation across program to optimize the noticing of information to public concerning on the importance of good dwelling sanitation and the low flies density in order to avoid from the occurance of diarrhea.
\end{abstract}

\section{Keyword : Diarrhea, Dwelling Sanitation, Flies Density}

\section{PENDAHULUAN}

Penyakit diare merupakan masalah kesehatan di dunia termasuk Indonesia. Menurut WHO dan UNICEF tahun 2004, terjadi sekitar 2 milyar kasus penyakit diare di seluruh dunia sekitar 1.9 juta anak balita meninggal setiap tahun, sebagian besar terjadi di negara berkembang. Dari semua kematian anak balita karena penyakit diare, $78 \%$ terjadi di wilayah Afrika dan Asia tenggara (Kemenkes RI, 2013).

Berdasarkan data dari Dinas Kesehatan Provinsi Jambi tahun 2016 dari 11 Kabupaten/Kota yang ada, kejadian diare di kota Jambi mengalami peningkatan dengan

\footnotetext{
${ }^{1}$ Jurusan Kesehatan Masyarakat Universitas Adiwangsa
}

jumlah penderita tertinggi dari tahun 2014 sebanyak 10.491 kasus dan tahun 2015 sebanyak 15.429 kasus dibandingkan dengan kabupaten/kota lainnya di Provinsi Jambi.

Berdasarkan data Dinas Kesehatan Kota Jambi tahun 2017 dari 20 Wilayah Kerja Puskesmas diketahui bahwa jumlah kejadian Diare di Puskesmas Tanjung Pinang Kota Jambi cenderung mengalami peningkatan dari tahun 2014 sebanyak 689 kasus, tahun 2015 sebanyak 1143 kasus dan tahun 2016 sebanyak 1821 kasus.

Berdasarkan data kejadian diare di Puskesmas Tanjung Pinang bulan Juni tahun 2017 diketahui bahwa dari 5 kelurahan yang ada Kelurahan Tanjung Pinang 
merupakan kelurahan dengan kasus diare terbanyak yaitu sebanyak 34 kasus, Kelurahan Kasang sebanyak 24 kasus, Kelurahan Kasang Jaya sebanyak 17 kasus, Kelurahan Rawasari sebanyak 16 kasus, Kelurahan Sijenjang sebanyak 25 kasus.

Tujuan penelitian ini untuk mengetahui faktor risiko kepadatan lalat dan sanitasi rumah dengan kejadian diare di Kelurahan Tanjung Pinang Kota Jambi tahun 2017.

\section{METODE PENELITIAN}

Penelitian ini adalah penelitian kuantitatif dengan desain Case Control. Dimana responden dikelompokkan menjadi dua yaitu penderita diare sebagai kasus dan bukan penderita diare sebagai kontrol, kemudian diteliti tentang sanitasi rumah dan kepadatan lalat selanjutnya dianalisa tentang hubungannya dengan kejadian diare.

Penelitian ini dilakukan di Kelurahan Tanjung Pinang Kota Jambi. Penelitian ini dilaksanakan pada bulan Agustus tahun 2017.

Populasi dalam penelitian ini adalah seluruh penderita diare di
Kelurahan Tanjung Pinang bulan Juni tahun 2017 sebanyak 34 kasus.

Sampel dalam penelitian ini adalah penderita diare di Kelurahan Tanjung Pinang pada bulan Juni tahun 2017 yang berjumlah 34 orang. Besar kontrol ditentukan berdasarkan pendekatan Case Control menggunakan metode Total Sampling dengan perbandingan 1:1, jumlah kasus sebanyak 34 orang, jumlah kontrol sebanyak 34 orang (orang sehat yang memiliki karakteristik yang sama dengan orang yang sakit seperti memiliki jamban, SPAL, sampah dan kepadatan lalat) dengan demikian jumlah sampel keseluruhan sebanyak 68 orang.

$$
\text { Data dikumpulkan }
$$
berdasarkan data primer (data yang diperoleh langsung dengan menggunakan pengukuran dan ceklis) data sekunder ( data yang diperoleh dari Dinas Kesehatan Provinsi Jambi, Dinas Kesehatan Kota Jambi, Puskesmas Tanjung Pinang (Sutanto, 2006).

\section{HASIL DAN PEMBAHASAN \\ Karakteristik Responden}

Tabel 1.Distribusi Frekuensi Karakteristik Responden Berdasarkan Jenis Kelamin dan Usia di Kelurahan Tanjung Pinang Kota Jambi Tahun 2017

\begin{tabular}{|c|c|c|c|c|c|c|c|c|c|c|}
\hline \multirow{3}{*}{$\begin{array}{c}\text { Jenis } \\
\text { Kelamin }\end{array}$} & \multicolumn{8}{|c|}{ Usia } & \multirow{2}{*}{\multicolumn{2}{|c|}{ Total }} \\
\hline & \multicolumn{2}{|c|}{$0-5$} & \multicolumn{2}{|c|}{$6-9$} & \multicolumn{2}{|c|}{ 10-19 } & \multicolumn{2}{|c|}{$>20$} & & \\
\hline & $\mathbf{N}$ & $\%$ & $\mathbf{N}$ & $\%$ & $\mathbf{N}$ & $\%$ & $\mathbf{N}$ & $\%$ & $\mathbf{N}$ & $\%$ \\
\hline Laki-Laki & 24 & 57.1 & 2 & 50 & 8 & 44.4 & 2 & 50 & 36 & 52.9 \\
\hline Perempuan & 18 & 42.9 & 2 & 50 & 10 & 55.6 & 2 & 50 & 32 & 42.1 \\
\hline Total & 42 & 100 & 4 & 100 & 18 & 100 & 4 & 100 & 68 & 100 \\
\hline
\end{tabular}

Berdasarkan Tabel 1, diketahui bahwa responden yang berusia $0-5$ tahun yang berjenis kelamin laki-laki sebesar $57,1 \%$ dan yang berjenis kelamin perempuan sebesar $42,9 \%$, responden yang berusia 6-9 tahun yang berjenis kelamin laki-laki sebesar $50 \%$ dan yang berjenis kelamin perempuan sebesar 50\%, responden yang berusia 10-19 tahun yang berjenis kelamin laki-laki sebesar $44,4 \%$ dan perempuan sebesar 55,6\%, responden yang berusia $>20$ tahun yang berjenis kelamin laki-laki sebesar $50 \%$ dan yang berjenis kelamin perempuan sebesar $50 \%$. 
Tabel 2. Distribusi Frekuensi Karakteristik Responden

Berdasarkan Pendidikan dan Pekerjaan

di Kelurahan Tanjung Pinang Kota Jambi Tahun 2017

\begin{tabular}{cccccccccccc}
\hline \multicolumn{1}{c}{ SD } & \multicolumn{1}{c}{ SMP } & \multicolumn{2}{c}{ SMA } & \multicolumn{2}{c}{ PT } & \multicolumn{2}{c}{$\begin{array}{c}\text { Belum } \\
\text { Sekolah }\end{array}$} & \multicolumn{2}{c}{$\begin{array}{c}\text { Bekerjaan } \\
\text { Bekerja }\end{array}$} \\
\hline Bendidikan \\
\hline N & \% & N & \% & N & \% & N & \% & N & \% & N & \% \\
\hline 12 & 17.6 & 6 & 8.8 & 4 & 5.8 & 4 & 5.8 & 42 & 61.7 & 68 & 100 \\
\hline
\end{tabular}

Berdasarkan tabel 2, diketahui bahwa dari 68 responden sebesar $17,6 \%$ responden merupakan siswa tingkat SD, 8,8\% merupakan siswa tingkat SMP, 5,8\% merupakan siswa tingkat SMA, $5.8 \%$ merupakan mahasiswa Perguruan Tinggi dan sebesar $61,7 \%$ belum bersekolah dikarenakan masih berusia $<6$ tahun. Dari tabel 4.2 diatas diketahui pula bahwa sebesar $100 \%$ responden belum bekerja.

\section{Analisis Univariat \\ Analisis univariat bertujuan untuk mengetahui distribusi frekuensi dari variabel independen yang meliputi sanitasi jamban, saluran pembuangan air limbah (SPAL), sampah dan kepadatan lalat dengan variabel dependen yaitu kejadian diare.}

Kejadian Diare

Tabel 3. Distribusi Frekuensi Kejadian Diare

di Kelurahan Tanjung Pinang Kota Jambi Tahun 2017

\begin{tabular}{ccc}
\hline Kejadian Diare & Frekuensi & $\mathbf{( \% )}$ \\
\hline Tidak Diare & 34 & 50 \\
Diare & 34 & 50 \\
\hline Total & $\mathbf{6 8}$ & $\mathbf{1 0 0}$ \\
\hline
\end{tabular}

Berdasarkan tabel 3, diketahui bahwa dari 68 responden, responden yang menderita diare sebesar $50 \%$

Sarana Pembuangan Kotoran dan yang tidak menderita diare (Jamban) sebesar $50 \%$.

Tabel 4. Distribusi Frekuensi Menurut Jamban di Kelurahan Tanjung Pinang Kota Jambi Tahun 2017

\begin{tabular}{ccc}
\hline Jamban & Frekuensi & \% \\
\hline Memenuhi Syarat & 28 & 41.2 \\
Tidak Memenuhi Syarat & 40 & 58.8 \\
\hline Total & $\mathbf{6 8}$ & $\mathbf{1 0 0}$ \\
\hline
\end{tabular}

Berdasarkan tabel 4, diketahui bahwa dari 68 responden, responden yang memiliki jamban memenuhi syarat sebesar $45,6 \%$ dan jamban yang tidak memenuhi syarat sebesar $54,4 \%$.

Saluran Pembuangan Air Limbah (SPAL)

Tabel 5. Distribusi Frekuensi Menurut SPAL di Kelurahan Tanjung Pinang Kota Jambi Tahun 2017

\begin{tabular}{ccc}
\hline SPAL & Frekuensi & \% \\
\hline Memenuhi Syarat & 40 & 58.8
\end{tabular}




\begin{tabular}{ccc} 
Tidak Memenuhi Syarat & 28 & 41.2 \\
\hline Total & $\mathbf{6 8}$ & $\mathbf{1 0 0}$ \\
\hline
\end{tabular}

Berdasarkan tabel 5, diketahui yang memiliki SPAL tidak memenuhi syarat sebesar $41,2 \%$.

bahwa dari 68 responden, responden yang memiliki SPAL memenuhi syarat sebesar $58,8 \%$ dan responden

Sampah

Tabel 6. Distribusi Frekuensi Menurut Tingkat Risiko Sampah di Kelurahan Tanjung Pinang Kota Jambi Tahun 2017

\begin{tabular}{ccc}
\hline Sampah & Frekuensi & \% \\
\hline Risiko Rendah & 22 & 32.4 \\
Risiko Tinggi & 46 & 67.6 \\
\hline Total & $\mathbf{6 8}$ & $\mathbf{1 0 0}$ \\
\hline
\end{tabular}

Berdasarkan tabel 6, diketahui bahwa dari 68 responden, responden yang memiliki tingkat risiko sampah rendah sebesar 32,4\% dan responden

yang memiliki tingkat risiko jamban tinggi sebesar $67,6 \%$.

\section{Kepadatan Lalat}

Tabel 7. Distribusi Frekuensi Menurut Tingkat Kepadatan Lalat di Kelurahan Tanjung Pinang Kota Jambi Tahun 2017

\begin{tabular}{ccc}
\hline Kepadatan Lalat & Frekuensi & \% \\
\hline Tidak Padat & 44 & 64.7 \\
Padat & 24 & 35.3 \\
\hline Total & $\mathbf{6 8}$ & $\mathbf{1 0 0}$ \\
\hline
\end{tabular}

Berdasarkan tabel 7, diketahui bahwa dari 68 responden, responden yang memiliki tingkat kepadatan lalat rendah sebesar $64,7 \%$ dan responden yang memiliki tingkat kepadatan lalat tinggi sebesar 35,3\%.

\section{Analisis Bivariat}

Analisis bivariat dilakukan untuk mengetahui hubungan antara

Tabel 8. Faktor Risiko antara Jamban dengan Kejadian Diare di Kelurahan Tanjung Pinang Kota Jambi Tahun 2017

\begin{tabular}{|c|c|c|c|c|c|c|c|c|}
\hline \multirow{3}{*}{ Jamban } & \multicolumn{4}{|c|}{ Kejadian Diare } & \multirow{2}{*}{\multicolumn{2}{|c|}{ Total }} & \multirow{3}{*}{$\mathbf{O R}$} & \multirow{3}{*}{$\begin{array}{c}p- \\
\text { value }\end{array}$} \\
\hline & \multicolumn{2}{|c|}{ Kontrol } & \multicolumn{2}{|c|}{ Kasus } & & & & \\
\hline & $\mathbf{N}$ & $\%$ & $\mathbf{N}$ & $\%$ & $\mathbf{N}$ & $\%$ & & \\
\hline Memenuhi Syarat & 19 & 55.9 & 9 & 26.5 & 28 & 41.2 & 3.519 & \\
\hline $\begin{array}{c}\text { Tidak Memenuhi } \\
\text { Syarat }\end{array}$ & 15 & 44.1 & 25 & 73.5 & 40 & 58.8 & $\begin{array}{l}(1.270- \\
9.750)\end{array}$ & 0.027 \\
\hline Total & 34 & 100 & 34 & 100 & 68 & 100 & & \\
\hline
\end{tabular}

Berdasarkan uji statistik diperoleh $p$-value sebesar 0,027 ( $p$ value < 0,05), hal ini membuktikan bahwa ada risiko antara sarana pembuangan kotoran (jamban) variabel independen yang meliputi jamban, SPAL, sampah dan kepadatan lalat dengan variabel dependen yaitu kejadian diare .

Faktor risiko antara sarana pembuangan kotoran (jamban) dengan kejadian diare 
peluang sebesar 2,322 kali untuk risiko terkena diare dibandingkan responden yang memiliki jamban memenuhi syarat dan jamban merupakan faktor penyebab diare.

Hasil penelitian dari Umiati (2010) juga menunjukkan bahwa ada hubungan yang bermakna antara sanitasi jamban dengan kejadian diare dengan $p$-value sebesar 0,018 .

Tabel 9. Faktor Risiko antara SPAL dengan Kejadian Diare di Kelurahan Tanjung Pinang Kota Jambi Tahun 2017

\begin{tabular}{|c|c|c|c|c|c|c|c|c|}
\hline \multirow{3}{*}{ SPAL } & \multicolumn{4}{|c|}{ Kejadian Diare } & \multirow{2}{*}{\multicolumn{2}{|c|}{ Total }} & \multirow{3}{*}{ OR } & \multirow{3}{*}{$\begin{array}{c}P- \\
\text { value }\end{array}$} \\
\hline & \multicolumn{2}{|c|}{ Kontrol } & \multicolumn{2}{|c|}{ Kasus } & & & & \\
\hline & $\mathbf{N}$ & $\%$ & $\mathbf{N}$ & $\%$ & $\mathbf{N}$ & $\%$ & & \\
\hline \multirow{2}{*}{$\begin{array}{c}\text { Memenuhi Syarat } \\
\text { Tidak Memenuhi } \\
\text { Syarat }\end{array}$} & 22 & 64.7 & 12 & 35.3 & 34 & 50 & \multirow{2}{*}{$\begin{array}{l}3.361 \\
(1.243- \\
9.088) \\
\end{array}$} & \multirow[b]{2}{*}{0.029} \\
\hline & 12 & 35.3 & 22 & 64.7 & 34 & 50 & & \\
\hline Total & 34 & 100 & 34 & 100 & 68 & 100 & & \\
\hline
\end{tabular}

Berdasarkan hasil uji statistik diperoleh $p$-value sebesar 0,029 ( $p$ value < 0,05), hal ini membuktikan bahwa ada risiko antara saluran pembuangan air limbah (SPAL) dengan kejadian diare. Dari hasil analisis juga diperoleh OR sebesar 3,361 (CL- 1,243-9,088) artinya responden yang memiliki SPAL tidak memenuhi syarat memiliki peluang sebesar 3,361 kali untuk menderita diare dibandingkan dengan responden yang memiliki Faktor risiko antara saluran
pembuangan air limbah
dengan kejadian diare Faktor risiko antara saluran
pembuangan air limbah
dengan kejadian diare Faktor risiko antara saluran
pembuangan air limbah
dengan kejadian diare Faktor risiko antara saluran
pembuangan air limbah
dengan kejadian diare . 


\section{Faktor risiko kepadatan lalat} dengan kejadian diare

Tabel 11. Faktor Risiko antara Kepadatan Lalat dengan Kejadian Diare di Kelurahan Tanjung Pinang Kota Jambi Tahun 2017

\begin{tabular}{|c|c|c|c|c|c|c|c|c|}
\hline \multirow{3}{*}{$\begin{array}{l}\text { Kepadatan } \\
\text { Lalat }\end{array}$} & \multicolumn{4}{|c|}{ Kejadian Diare } & \multirow{2}{*}{\multicolumn{2}{|c|}{ Total }} & \multirow{3}{*}{$\mathbf{O R}$} & \multirow{3}{*}{$\begin{array}{c}p- \\
\text { value }\end{array}$} \\
\hline & \multicolumn{2}{|c|}{ Kontrol } & \multicolumn{2}{|c|}{ Kasus } & & & & \\
\hline & $\mathbf{N}$ & $\%$ & $\mathbf{N}$ & $\%$ & $\mathbf{N}$ & $\%$ & & \\
\hline \multirow{2}{*}{$\begin{array}{c}\text { Rendah } \\
\text { Tinggi }\end{array}$} & 21 & 61.8 & 23 & 67.6 & 44 & 64.7 & \multirow{3}{*}{$\begin{array}{c}0.773 \\
(0.285- \\
2.094)\end{array}$} & \multirow[b]{2}{*}{0.800} \\
\hline & 13 & 38.2 & 11 & 32.4 & 24 & 35.3 & & \\
\hline Total & 34 & 100 & 34 & 100 & 68 & 100 & & \\
\hline
\end{tabular}

Berdasarkan uji statistik diperoleh $p$-value sebesar 0,800 ( $p$ value > 0,05), hal ini membuktikan bahwa tidak ada risiko antara kepadatan lalat dan kejadian diare. Hasil analisis juga memperoleh OR sebesar 0,773 (CL $0,285-2,904)$ artinya responden yang memiliki kepadatan lalat tinggi memiliki peluang sebesar 0,773 kali untuk menderita diare dibandingkan responden yang memiliki kepadatan lalat rendah dan merupakan faktor protektif terhadap diare. Hasil penelitian dari Kotrun Nida (2014) juga menunjukkan hasil bahwa tidak ada hubungan antara kepadatan lalat dengan kejadian diare dengan $p$ value sebesar 0,365 ( $p$-value > 0,05).

Menurut hasil penelitian Rudianto dan Azizah (2003), terdapat perbedaan kepadatan lalat dengan kejadian diare dimana semakin tinggi tingkat kepadatan lalat maka semakin tinggi angka kejadian diare. Jalur transmisi penularan penyakit diare antara lain melalui air dan makanan serta binatang arthopoda secara mekanis

\section{SIMPULAN}

Sarana pembuangan kotoran (jamban) merupakan faktor risiko terjadinya diare di Kelurahan Tanjung Pinang Kota Jambi Tahun 2017 dengan OR sebesar 3,519 (CI 1,270-9,750) dan p-value sebesar
$0,027$ (p-value $<0,05)$; Saluran pembuangan air limbah (SPAL) merupakan faktor risiko terjadinya diare di Kelurahan Tanjung Pinang kota Jambi Tahun 2017 dengan OR sebesar 3,361 (CI 1,243-9,088) dan p-value sebesar 0,029 ( $p$-value < $0,05)$; Sampah merupakan faktor risiko terjadinya diare di Kelurahan Tanjung Pinang Kota Jambi Tahun 2017 dengan OR sebesar 4,148 (CI 1,368-12,580) dan $p$-value sebesar 0,019 ( $p$-value $<0,05$ ); Kepadatan lalat merupakan faktor protektif terhadap kejadian diare di Kelurahan Tanjung Pinang Kota Jambi Tahun 2017 dengan OR sebesar 0,773 (CI $0,285-2,094)$ dan $p$-value sebesar $0,800$ ( $p$-value $>0,05)$.

\section{DAFTAR PUSTAKA}

Dinas Kesehatan Provinsi Jambi. (2016). Profil Kesehatan Provinsi Jambi Tahun 2016.

Dinas Kesehatan Provinsi Jambi. (2015). Profil Kesehatan Provinsi jambi Tahun 2015.

Dinas Kesehatan Kota Jambi. (2016). Laporan Tahunan Dinas Kesehatan Kota Jambi.

Nida, Kotrun. (2014). Hubungan Pengelolaan Sampah RT terhadap Daya Tarik Vektor Musca Domestica (Lalat Rumah) dengan Risiko Diare pada Baduta di Kelurahan 
Ciputat Tahun 2014. (Skripsi).

(Diakses 16 Agustus 2017)

Puskesmas Tanjung Pinang. (2017).

Laporan Bulanan Kejadian

Diare.

Rudianto, Heru dan R. Azizah.

(2003). Studi Tentang

Perbedaan Jarak Perumahan

Ke TPA Sampah open

Dumping dengan Indikator

Tingkat Kepadatan Lalat dan

Kejadian Diare di Desa Kenep

Kecamatan Beji Kebupaten

Pasuruan. Jurnal Kesehatan

Lingkungan, Vol.1, No. 2, Januari 2005.

Saleh, Muh dan Lia Hijriani Rachim.

(2013). Hubungan Kondisi

Sanitasi Lingkungan dengan

Kejadian Diare pada Anak

Balita di Wilayah Kerja

Puskesmas Baranti Kabupaten

Sidkap. UIN Alauddin

Makasar. (Skripsi). (Diakses

16 Agustus 2017)

Sutanto. (2006). Analisis Data SPSS.

FKM UI.

Umiati. (2010). Hubungan antara

Sanitasi Lingkungan dengan Kejadian Diare pada Balita di Wilayah Kerja Puskesmas Nogosari Kabupaten Boyolali Tahun 2009. UMS (Skripsi). (diakses 26 Mei 2017). 